\title{
Nanodelivery systems for Alzheimer's disease: Prospects of natural therapeutic agents
}

\author{
Oluwatoyin A. Odeku*, Tolulope O. Ajala \\ Department of Pharmaceutics and Industrial Pharmacy, Faculty of Pharmacy; University of Ibadan, Ibadan, Nigeria.
}

\begin{tabular}{l}
\hline ARTICLE INFO \\
\hline Received on: $31 / 10 / 2020$ \\
Accepted on: 26/02/2021 \\
Available online: 03/11/2021 \\
\\
\hline Key words: \\
Nano-delivery, Alzheimers' \\
disease, bioactive agents, \\
blood-brain barrier, delivery \\
systems.
\end{tabular}

\begin{abstract}
Diseases that cause deterioration of the neurons are many and Alzheimer's disease (AD) is a typical example. The prevalence of $\mathrm{AD}$ is increasing with a huge impact on the family, society, and the economy of nations. The central nervous system and its periphery have barriers which are crucial interfaces preventing the entrance of awkward materials. Among these barriers, the blood-brain barrier (BBB) is the most selective and comprises cells coupled with fitted intersections. Nanosized carriers have the prospect for administering drugs to the brain and examples include nanoemulsions, those based on solid lipids and those based on solid and liquid lipids. These formulations can encapsulate active molecules and target necessary transport systems in the brain, thus enabling drug uptake through the BBB. Nanoparticles are of different types and are obtained using diverse techniques and materials. What is common to all nanocarriers is the small sizes and specificity in site targeting. Conventional drugs used in the treatment of AD and bioactive agents can be designed as nanocarriers for improved efficacy. This paper elucidates the use of nanoparticles in managing $\mathrm{AD}$ while touching on the prospects of natural therapeutic agents and highlighting future perspectives.
\end{abstract}

\section{INTRODUCTION}

Neurodegenerative diseases affect over 10 million people with an estimated increase of $20 \%$ in 10 years to come; this is not surprising since the aging populace is increasing, and in some countries, life expectancy is growing (Spuch and Navarro, 2011). Neurodegenerative diseases have been reported to rank fourth among death-causing ailments, such as cardiovascular problems, and cancers of various types in the Western world (OECD, 2010). The diseases have many similarities on a subcellular level, can begin at any age, but are much common among the elderly (Forlenza et al., 2010). The most common neurodegenerative diseases are amyotrophic lateral sclerosis, Huntington's disease, frontotemporal dementia, prion diseases, and Alzheimer's disease (AD) (Bertram and Tanzi, 2005). Among these diseases, Parkinson's syndrome and AD are the most common, producing outstanding debilitating conditions of significant public health

"Corresponding Author

Oluwatoyin A. Odeku, Department of Pharmaceutics and Industrial Pharmacy, Faculty of Pharmacy; University of Ibadan, Ibadan, Nigeria. E-mail: o.odeku@ui.edu.ng; pejuodeku@yahoo.com concern (Spuch and Navarro, 2011). Health statistics have shown that among millions of people suffering from dementia, a majority have AD and are elderly (Morgan, 2011). The disease (AD) is a neurodegenerative disorder, first observed as senile dementia and described over a century ago by Alois Alzheimer (Ferri et al., 2005; Nazem and Mansori, 2008). Learning and memory impairment are typical clinical manifestations of $\mathrm{AD}$, while the pathology can be described by gross cerebral atrophy indicative of neuronal loss (Mucke, 2009). It is a multifactorial disease with several contrivances and conduits having somehow permanent pathology, and current treatments are for lowering related signs (Nasem and Mansori, 2011). Some of the causes of AD have been shown to include deficiency of acetylcholine, imbalance in the glutamatergic system, deposition of phosphorylated tau proteins, and amyloid plaques (Ayaz et al., 2017; Khalil et al., 2018).

The occurrence and frequency of $\mathrm{AD}$ increases with age, but degeneration of nervous tissues generally commence after several years, up to a decade or more, before the symptoms of $\mathrm{AD}$ manifests in the patient (Mortimer et al., 2005; Nestor et al., 2004; Sloane et al., 2002). AD is a disease of major public health concern because the elderly population is increasing globally. $\mathrm{AD}$ progresses slowly, the signs are somewhat silent in the early 
stages, and its effect deteriorates as time goes on; the indicators could be the inability to remember recent events, inability to obtain new information, poor judgment and missing the way home are also very common among patients (Rocha, 2013). Patients with $\mathrm{AD}$ experience behavioral instability, cerebral dysfunction, and deficiency in normal life activities. After a couple of years, AD patients begin to suffer from three-dimensional awkwardness which oftentimes makes them unaware of their surroundings. The situation leads them to an overall indifference to happenings in their surroundings and they may become a great burden to their loved ones due to poor emotional regulation. Inability to write and walk properly also occurs with time because the patients also lose motor handling abilities (Rocha, 2013). All these lead to a huge socio-economic burden on the family and the overall healthcare delivery system (Ali et al., 2017). An estimate by the United States National Institute of Health reported that the annual cost of managing AD is $\$ 100$ annually (Roney et al., 2005). This shows the extent of the economic burden for families and society at large. There is also the silent but heavy cost of loss of man-hours and funds because $\mathrm{AD}$ patients require to be looked after by relatives or hired caregivers. It is worrisome, therefore, that conventional medical approaches seem incapable of terminating the disease or reversing the progression irrespective of early diagnosis when possible. Furthermore, the fundamental mechanisms of AD are not completely understood, although there are diverse methodologies geared toward impeding the disease progression (Citron, 2010).

\section{Active Pharmaceutical Agents in the Pursuit of a Cure for AD}

Some orally administered pharmaceutical agents that are clinically approved to treat $\mathrm{AD}$ include memantine, galantamine, donepezil, tacrine, and rivastigmine (Pasic et al., 2011). Memantine is a glutamatergic system modulator, while the remaining four drugs are cholinesterase inhibitors (Ayaz et al., 2015; Kamal et al., 2015). These medications have narrow activity in addition to untoward side effects; for example, tacrine is hepatotoxic (Watkins et al., 1994). Unfortunately, the majority of the drugs administered to the patients never enter the brain in effective concentrations due to partial or total hepatic breakdown and inability to pass through the biological barrier of the brain. Higher drug concentrations, which can produce toxicity in vital organs of the body, may be thus required due to the inefficient drug utilization. In addition, some of the therapeutic agents have poor solubility while others have outright insolubility in aqueous solutions, making their oral or parenteral delivery quite tasking. Recent outcomes from clinical evaluations carried out in patients having mild to moderate dementia have established the need to search natural sources for more effective but safe substitutes (Cummings et al., 2014; Yiannopoulou and Papageorgiou, 2013).

Therapies found useful for AD have different mechanisms for tackling the problem of neurodegeneration. For example, therapies called cholinesterase inhibitors impede acetylcholinesterase, thus increasing the concentration of acetylcholine in the connection point and upgrading transmission enabled in the neurons by choline. Examples are donepezil, galantamine, tacrine, and rivastigmine (Zarotsky et al., 2003). Non-steroidal anti-inflammatory drugs are also helpful as they inhibit pro-inflammatory mediators such as cyclooxygenase which is neurotoxic (Ho et al., 2001). The excessive generation of reactive oxygen or nitrogen species has been proposed as one of the causes of neurodegeneration (Emerit et al., 2004). These free radicals are released during inflammatory reactions or normal oxidative metabolism, auto-oxidation of certain neurotransmitters. Antioxidants are useful in handling dementia by scavenging reactive oxygen and nitrogen species which are causative agents for oxidative injury in neurons. Some compounds are capable of inhibiting monoamine oxidase which is an enzyme responsible for the collapse of dopamine at the neuronal junction. Dopamine inhibitors cause it to increase, thus helping in the improvement of dementia (Stafford et al., 2007).

Harmane and harmaline are alkaloids that excite dopamine release from striatal cells (Schwarz et al., 2003), thus improving dementia. Compounds that also prevent the aggregation of $\mathrm{A} \beta$ fragment, a precursor in the formation of $\beta$ amyloid plaque, are also useful. For example, previous studies have shown that curcumin helps in plaque disorder and restoration of inflamed nerves in vivo (Taniguchi et al., 2005). Metal chelators are indirect antioxidants that chelate divalent ions like copper and zinc which have roles in the clumping of alpha-beta portions (Craig et al., 2005).

\section{Natural Products as Sources of Drugs for AD}

In addition to synthetic drugs approved by various regulatory establishments, studies on herbal extracts containing single or multiple herbs or a blend of herbs and minerals have been conducted for their activity in protecting the neurons which slow down the advancement of AD symptoms. Examples of such plants which have been evaluated and found possessing anti-Alzheimer's properties include Abies koreana, whose essential oil was extracted, evaluated, and found to improve memory in vivo using the scopolamine-induced amnesia mice model (Kim et al., 2006). Bacopa monnieri also enhanced intellectual capacity and memory by helping to reduce the loss of neurons using an AD animal model in past studies (Saini et al., 2012; Uabundit et al., 2010).

Furthermore, different plant extracts have demonstrated activities through diverse mechanisms. Examples include Salvia officinalis, Cassia obtusifolia, and Desmodium gangeticum, which all act through cholinesterase inhibition; Moringa oleifera, a common plant in West Africa, acts through the modification of monoamines and antioxidant effect, while Ginkgo biloba acts through anti-amyloid aggregation and antioxidant action (DeKosky et al., 2008). Dried ginger (Zingiber officinale) has demonstrated butyrylcholinesterase inhibitory properties and antagonistic activity against calcium ions, all leading to AD treatment (Ghayur et al., 2008). Salvia officinalis and D. gangeticum also demonstrate an antioxidant effect. The seeds of Cassia obtisufolia have also shown the capacity to protect neurons from degeneration when tested on animals; the mechanism was found to be a reduction of ancillary deregulation of calcium ions and organelle contaminant (Obulesu and Rao, 2011). The following are natural bioactive substances with proven activity toward the treatment of AD.

\section{Colostrinin $^{\mathrm{TM}}$}

Colostrinin $^{\mathrm{TM}}$ is a product of ReGen Therapeutics; it consists of varied polypeptides extracted from the colostrum of sheep (Williams et al., 2011). Colostrum is a form of milk produced by the mammary glands of mammals. Mammals usually produce milk in the third trimester of pregnancy and this milk is called colostrum. Oral tablets of colostrinin have shown improved mental 
state with the development of new memories in 15 Alzheimer's patients better than controls (Leszek et al., 1999). Additionally, in an extensive double-blind study, Bilikiewicz and Gaus (2004) reported that low-dose colostrinin was effective in upholding reasoning and attending to routine tasks in 105 Alzheimer's patients over a period of 15 weeks. The drug was also well tolerated by the patients; it is now officially available in Australia and US as a nutraceutical.

\section{Resveratrol (trans-3,4',5-trihydroxystilbene)}

Resveratrol is commonly referred to as a wine polyphenol and is present in grapes (Vitis vinifera L.; family Vitaceae). The wine polyphenol is a phenylpropanoid ester and a stilbenoid with various activities, which have been investigated for preventive, antioxidant, and relevance in $\mathrm{AD}$ treatment. Resveratrol rummages reactive oxygen species; it also causes an increase in the number of receptors on the surface of target cells, and has in vitro and in vivo neuroprotective properties against oxidative stress (Kim et al., 2010; Rossignol et al., 2008). Resveratrol is reported to promote the removal of alpha-beta within the cells by enabling the breakdown of proteasomes (Marambaud et al., 2005). Feng et al. (2009) also suggested the disruption of $A \beta 42$ hydrogen bonding, thus preventing fibril formation with a ranking of resveratrol $>$ catechin $>$ curcumin $>$ piceid $>$ ginkgolides; it can destabilize preformed $\mathrm{fA} \beta 42$ in vitro (Lee et al., 2007).

Resveratrol has been subjected to various clinical trials for obesity, diabetes, cancer, cardiovascular diseases, and neurological disorders. The outcome of these trials has also varied due to diverse investigational surroundings and dissimilar doses (Berman et al., 2017; Pezzuto, 2019). One item of challenge in all the trials is the poor bioavailability of resveratrol which points to the need for more evaluations (Ramírez-Garza et al. 2018).

\section{Curcumin (diferuloylmethane)}

Curcumin obtained from turmeric Curcuma longa L. (Zingiberaceae) is a polyphenolic ingredient, and is quite popular in traditional Indian cuisine. Curcumin possesses higher absorptivity to the blood-brain barrier and minimal toxicity (Yang et al., 2005). Curcumin efficiently impedes the formation of alphabeta oligomers, reduces amyloid in vivo, and binds prevailing abnormal patches (Yang et al., 2005). The neuroprotective effect of curcumin has been attributed to the inhibition of microglial activation (Lee et al., 2007). Past reports have shown that curcumin possesses anti-inflammatory and free radical scavenging properties (Aggarwal et al., 2003).

The effect of curcumin on human cognitive control was conducted by randomization within 8 years and only two yielded positive outcome on memory improvement (Baum et al., 2008; Kuszewski et al., 2018; Lee et al., 2014). Hishikawa et al. (2012) conducted another study that concentrated on the properties of curcumin to improve social and psychosomatic indicators of dementia in three AD patients (Hishikawa et al., 2012).

\section{Alkaloids}

These are varied and typical examples are physostigmine, nicotine, melatonin, and memantine. Generally, alkaloids are $\mathrm{ACHe}$ inhibitors and have been reported to assist in vivo intellectual roles in both patients having dementia and normal people (Howes and Houghton, 2009). A few of them are discussed below.

\section{Physostigmine}

Eserine or physostigmine is a naturally occurring organic compound containing nitrogen, generally called alkaloid. It was isolated from Physostigma venenosum Balf seeds (family: Leguminosae). Eserine has a pyrrole-indole skeleton which is a potent, short-acting reversible inhibitor of ACHe (Kamal et al., 2000). To improve the efficacy and pharmacokinetic outlook of physostigmine, numerous equivalents of it have been investigated. For example, rivastigmine, which is the carbamate type, has been the most therapeutically effective and is currently certified for use in AD patients who show signs of mild to moderate dementia (Onor et al., 2007).

\section{Nicotine}

Nicotine is an alkaloid from the family Solanaceae that possesses in vitro effects on multiple stages of amyloidogenesis attributed to the presence of $\mathrm{N}$-methyl pyrrolidine moieties (Nordberg et al., 2002). Nicotine successfully inhibits the development and propagation, in addition to disrupting preformed $\mathrm{fA} \beta 40$ and $\mathrm{fA} \beta 42$ but could not break down the aggregates to their respective forms (Ono et al., 2002). However, Nordberg et al. (2002) reported that the concentration of $A \beta$ plaque was considerably lowered in mice into which foreign genes have been inserted and compared with controls after treatment for 5.5 months. Nicotine also showed undesired side effects in vivo studies where its presence increased the accumulation of tau proteins and the addition of phosphoryl groups to them (Oddo et al., 2005).

\section{Melatonin}

Melatonin is an anti-aggregation phytoconstituent available in numerous organisms and possesses the ability to effectively cross the blood-brain barrier (BBB). Melatonin promotes random coil conformations of $\mathrm{A} \beta$ peptides by unsettling the salt connections existing among the histidine and asparagine residues, thus expediting clearance (Pappolla et al., 1998). Its antiaggregation properties make it invaluable in the management of $\mathrm{AD}$.

\section{Homotaurine}

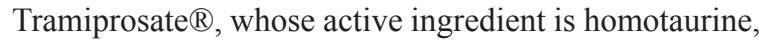
is one of the foremost natural products to demonstrate an anticlumping pathway (Gervais et al., 2007). Homotaurine or 3-aminopropanesulfonic acid can be found in seaweed (Ito et al., 1977). Bellus Health, formerly known as Neurochem, markets homotaurine as a memory protective nutraceutical called Vivimind $^{\mathrm{TM}}$ in some countries (Neurochem, 2010).

\section{Huperzine A}

One of the metabolites isolated from Huperzia serrata (Thunb.) Trevis, from the family Lycopodiaceae, is Huperzine A. The isolate has been extensively investigated as a reversible inhibitor of acetylcholinesterase. Huperzine A improves perceptive purposes in animal and elderly patients of $\mathrm{AD}$ with narrow adverse reactions (Howes and Houghton, 2009). Huperzine A is also neurotrophic (Tang et al., 2005) and neuroprotective and has found usefulness in handling symptoms of AD in China (Wang et al., 2006). In addition, the powder of $H$. serrata has been commercialized the US for alleviating retention deficiency (Ma et al., 2007). A usefulness and 
safety evaluation of Huperzine A showed it to be well tolerated and to meaningfully mend cerebral performance and events of daily life in AD patients (Wang et al., 2009).

\section{The Peculiarities of Central Nervous System in Offering Answers to AD}

Drug delivery for tackling any disease of the central nervous system requires targeting the brain if there would be a success in therapy. However, it is not easy to transport drugs to the central nervous system because of the BBB which hinders access (Patel et al., 2012). The BBB majorly protects the brain from harm by controlling the selective carriage of supplies to the brain. The selective barrier to the brain consists of microglial chambers, pericytes, astrocytes, and endothelial cells that have tight junctions in between them (Gao et al., 2013; Rubin and Staddon, 1999). The existence of closely packed intersections between adjacent cells embedded in larger ones, thus causing the passage of materials through the BBB to occur by the transcellular route. In addition, the combination of tight junctions and the two membranes (abluminal and luminal), which covers the inward part of the receptacle, typifies the BBB with low absorptivity to large, lipophilic, and ionic materials. Macromolecules like proteins and smaller molecules are restricted from passing through the BBB except by interaction with specific receptors and carriers resident in the lumen of cells located within larger ones (Rubin and Staddon, 1999). Receptor-mediated transcytosis is a means of transport using ligand-specific receptor systems and is useful for larger molecules like insulin and certain hormones to enter the brain (Gao et al., 2013; De Rosa et al., 2012).

To dodge the selective barrier and transport medicines to the brain, three approaches that have been employed in the past include pharmacological, invasive, and physiological.

\section{Pharmacological slant}

In the pharmacological slant, drugs are modified to shrink the comparative amount of water-loving segments, thus improving the prospect of giving passage to the drug through the BBB (Pardridge, 2005). For example, creatine is a polar compound that cannot cross the BBB, yet it possesses neuroprotective properties. To apply the pharmacological method of slighting the BBB for creatine, a derivative of the drug with hydrophobic nature was produced to combat neurodegenerative conditions. The disadvantage of this procedure is a reduction in the desired therapeutic activity of the modified drug compared to the original drug, even though alteration enabled their crossing of the BBB.

\section{Invasive method}

The invasive method was used to boost drug transfer to the brain by mechanically breaching the BBB using intracerebroventricular infusion and convection. The drawbacks include higher costs due to patient hospitalization, extended opening periods of the BBB, infections, damage to neurons, and possible damage to the BBB (Pardridge, 2005).

\section{Physiological approach}

The physiological approach leverages the intrinsic recognition of the BBB for essential substances, like glucose, growth hormones, insulin, and low-density lipoproteins, which helps the brain in metabolism and optimal subsistence. The drug to be transported is altered to bear a resemblance to the nutrient vehicle of the blood- brain barrier or joined to a ligand, thus gain recognition as receptors at the BBB (Pehlivan, 2013). The problem with this method is that the drug could dissociate from the ligand and hurt other body structures.

\section{Nanotechnology as a Solution to Effective Drug Delivery in AD Management}

Nanotechnology is a broad term referring to a field of applied science and technology-centered on the regulation of substance at the molecular level ranging from 1 to 1000 nanometers, and the designing of equipment within that scope (Guar and Batia, 2008). Nanotechnology draws from many disciplines such as physics, chemistry, geography, biology, engineering agriculture, biotechnology, pharmacy, and medicine. In the previous decade, nanoparticulate materials were quite attractive for commercial development due to their diverse usefulness. Nanoparticles have been useful in the manufacturing of cosmetics and personal care products; electrical and electronic supplies and consumables; pharmaceuticals and medical devices; in addition to diagnostic tools in debilitating conditions, discovery of new active pharmaceutical ingredients, and solving bioavailability (Joshi et al., 2012).

Nanotechnology is also a promising method of early diagnosis and management of $\mathrm{AD}$. In diagnosis, nanoparticles can identify minute quantities of biological markers for $\mathrm{AD}$ and other numerous biological indicators in the brain, before significant damage occurs (Nazem and Mansoori, 2012). Interestingly also, nanoparticles can be used to detect the pathology of $\mathrm{AD}$, autonomous of the brain standby. Most of the methods for early detection using nanoparticles are centered around the presence of amyloid patches using magnetic resonance imaging (Brambilla et al., 2011). When $\mathrm{AD}$ onset begins, amyloid peptides begin to accrue and as the disease matures, they can be easily observed (Brambilla et al., 2011). Magnetic iron oxide nanoparticles, which are medically useful in the liver have also been noted for prospective use in the brain. Furthermore, iron oxide contrast agents have been reportedly used to identify sections of the brain having a high attraction for amyloid- $\beta$ peptides by using mice brains when they were deployed across the selective barrier of the brain (Brambilla et al., 2011). The nanoparticles could detect and possibly remove peptides associated with the inception of AD. The deadlock for progress in this direction can only be removed until human testing can be adjudged safe, especially with the handling of the BBB for an efficient crossing of the nanoparticles. The growing interest in the use of nanodrug delivery for $\mathrm{AD}$ as seen in the scientific literature from two search engines, PubMed and Science Direct, is shown in Figure 1. Figure 1 shows that the number of scientific publications in PubMed increased from 55 in 2010 to almost 653 in the year 2020, indicating a 12 -fold increase in publications.

Since the different approaches employed to tackle AD had been limited by the BBB which hinders the penetration of many drugs, yet some other methods which circumvent the BBB have significant drawbacks, the use of novel carriers for drugs becomes imperative. The progress of nanoparticle-based drug transport methods that could cross the $\mathrm{BBB}$ is novel and can benefit the treatment and management of AD. For example, the drug rivastigmine inhibits the enzyme in the brain which destroys acetylcholine, thus improving cognitive behavior and function in $\mathrm{AD}$ patients. The low concentration of rivastigmine reaching the brain however limits its clinical use. A study in an animal model has shown a significant increase in the 


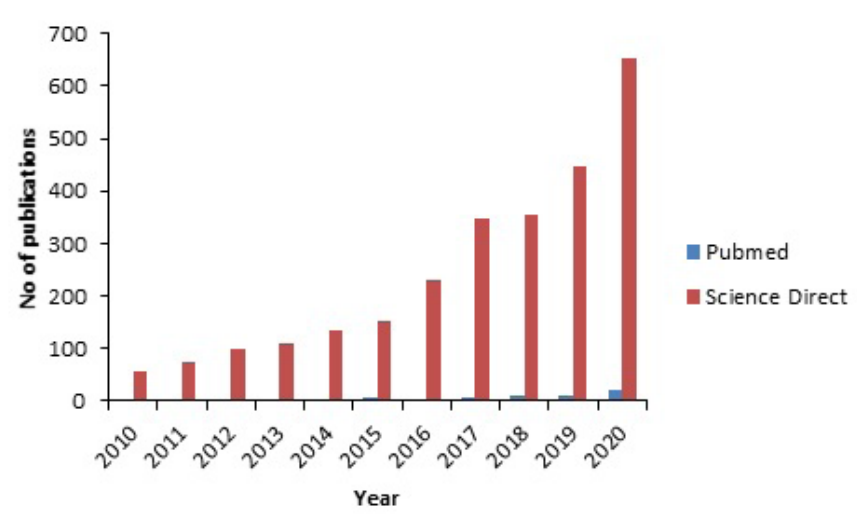

Figure 1. Scientific literature published on nanodelivery drug systems for $\mathrm{AD}$ per year.

concentration of rivastigmine reaching the brain when it was loaded into nanocarriers (Brambilla et al., 2011).

\section{Unique Studies on the Use of Nanodelivered Drugs for AD}

The bioavailability and brain delivery of active pharmaceutical ingredients have been reported to have great improvement using peptide-polymer conjugates (Antunes et al., 2013). These conjugates achieve such by promoting the pharmacokinetic profiles of the drugs through an increase in their molecular mass, thus offering protection from proteolytic enzymes (Antunes et al., 2013). For example, peptides have low bioavailability and metabolic firmness in a normal physiological environment, and the conjugation of peptides to polymers in nanoparticle drug carrier schemes has prospects in handling neurodegenerative diseases by improving the stability and bioavailability (Gentilucci et al., 2010).

Nanoparticles of functional siRNA were prepared using peptide-tagged polyethylene glycol (PEG)-related chitosan polymer and used against the Ataxin-1 gene in an in vitro model of neurodegenerative disorder. The outcome showed the suppression of SCA1 protein within two days, which is of great influence on the therapy of AD, Parkinson's disease, and others (Malhotra et al., 2013). The beneficial influence of using nanoparticulate formulations in the management of neurodegenerative diseases has been expanded with the use of cerium oxide nanoparticles. Their unique characteristics include the average nanosize which enables its crossing of the BBB in addition to its antioxidant properties (Naz et al., 2017).

\section{Typical Examples of Nanoparticles that have Shown Promise}

Typical examples of nanoparticles that have shown promise include liposomes (Mourtas et al., 2014), niosomes, polymeric nanoparticles, micelles (Hagl et al., 2015), solid lipid nanoparticles (SLN; Dang et al., 2014), nanostructured lipid carriers (NLC; Puglia et al., 2012), and nanoemulsions (Sood et al., 2014). Methods that have been used in the preparation of nanodelivery drugs are presented in Table 1. Nanoparticulate drug delivery systems have diverse benefits such as the incorporation of oily and aqueous drugs, high drug loading, improved stability, scaling up, avoidance of organic solvent, and drug targeting (Muller et al., 2000).

The conveyance of nanoparticles to the brain in the amelioration of neurodegenerative diseases is influenced by diverse factors. They include particle size, diffusion of molecules to the brain parenchyma, modification of BBB in neurological disorders, and formation of corona biomolecules on nanoparticle surfaces (Masserini, 2013). Particle sizes that have been reported to cross the BBB vary depending on the drug, route of administration, and formulation type. For example, intravenous dendrimer of about 12 $\mathrm{nm}$ crossed, while larger particles could not (Sarin et al., 2008). In another study, orally administered gold nanoparticles with a size lower than $58 \mathrm{~nm}$ were reported to have crossed the BBB (Schleh et al., 2012). The SLNs and NLCs contain solid lipid matrices obtained from triglycerides, waxes, and complex mixtures of glycerides; the lipophilic structures of these preparations enable the crossing of the BBB by endocytic mechanism (Kreuter, 2001; Wang et al., 2002; Wissing et al., 2004).

Ginkgo biloba extract (GbE) prepared as phytosomes was orally administered to rats and compared to sodium nitrite treatment; the results showed that GbE-phytosomes increased the action of enzymes involved in scavenging free radicals in all parts of the brain (Naik et al., 2006). Furthermore, two formulations (niosome and tablets) containing G. biloba extract were prepared and the in vivo distribution in rats was studied. The content of flavonoid glycoside biomarker in the blood, lung, and brain of the rats was considerably higher for the GbE-niosome-treated rats when compared to the tablets (Jin et al., 2013). The rats which received the tablets had no flavonoid glycosides in the brain tissue, but they were observed in those that received niosomes. The study reported a higher accumulation of $\mathrm{GbE}$ in the brain, and the

Table 1. Methods that have been used in the preparation of nano delivery drugs.

\begin{tabular}{|c|c|c|}
\hline S.No & Method & References \\
\hline 1. & High-Pressure Homogenization & Lee et al., 2014a; 2014b \\
\hline 2. & Microfluidization & Jo and Kwon, 2014 \\
\hline 3. & Particle replication in non-wetting templates & Gratton et al., 2007; Chu et al., 2013; Galloway et al., 2013 \\
\hline 4. & Spray drying & Ali and Lamprecht, 2014 \\
\hline 5. & Spontaneous emulsification or solvent diffusion & Calvo et al., 1997; Murakami et al., 1999 \\
\hline 6. & Nanoprecipitation & Bilati et al., 2005; Mazzarino et al., 2014 \\
\hline 7. & Polymer polymerization & Boudad et al., 2001; Souto et al., 2012 \\
\hline 8. & Supercritical fluid technology & Hu et al., 2011 \\
\hline 9. & Emulsion solvent evaporation & Mainardes et al., 2005; Mainardes and Gremião, 2012 \\
\hline 10. & Coacervation & Dong et al., 2013; Arora et al., 2011 \\
\hline 11. & Sonication & da Silva et al., 2014 \\
\hline
\end{tabular}


pharmacokinetic profiles and in vivo drug distribution indicate the superior properties of niosomes in conditions affecting the brain such as ADs compared to tablets (Fonseca-Santos et al., 2015).

Liposomes have been used as nanocarriers to overcome the BBB using the intranasal pathway (Mainardes et al., 2006). Studies on liposomes loaded with rivastigmine prepared by lipid hydration for intranasal delivery to the brain showed that intranasally delivered liposome was 10 -fold higher in plasma compared to the intranasally or orally delivered free drug (Arumugam et al., 2008). In addition, rivastigmine-loaded liposome administered intraperitoneally to $\mathrm{AD}$ animal model indicated that the liposome formulations demonstrated the highest inhibition of AChE showing its potential in alleviating AD (Mutlu et al., 2011).

Nanoparticles of poly(D, L-lactide-co-glycolide) and poly(butyl cyanoacrylate) loaded with rivastigmine were produced by emulsion polymerization and adapted method of nanoprecipitation; the rivastigmine-loaded nanoparticles were administered to mice with scopolamine-induced amnesia. The results showed that mice given rivastigmine-loaded nanoparticles showed a considerable reduction in amnesia, while the control group which received rivastigmine dissolved in saline did not reveal any improvement in memory or learning capacities (Joshi et al., 2010).

To improve the uptake of rivastigmine to the brain through intranasal delivery, chitosan nanoparticles were produced by ionic gelation and the concentration of the drug in vivo was studied using confocal laser scanning. The results indicated that the amount of rivastigmine in the brain was found to be profoundly higher when matched to rivastigmine solution using the same intranasal or intravenous routes (Fazil et al., 2012)

Curcumin-conjugated nanoliposomes prepared and administered by injection in vivo in mice showed that the $\mathrm{A} \beta$ deposits of the hippocampus and neocortex of the animals were specifically stained (Lazar et al., 2013). This is considered a strong reflection that the nano-liposomes can find application in diagnosis and directed drug transfer for AD.

Studies have shown that microemulsions for transdermal delivery can be used in the management of $\mathrm{AD}$ with improved outcomes. Patel et al. (2013) compared the results of microemulsions loaded with huperzine A for transdermal usage and huperzine A suspension given orally to mice. The group for huperzine A microemulsions exhibited enhanced perceptive roles when related to mice to which Huperzine A suspension was administered peroral. Curcumin-loaded nanoemulsions administered through the intranasal route have also led to significant improvement in learning and memory in animals compared with animals treated with pure curcumin (Sood et al., 2013). Some patented nanoparticulate delivery systems for neurodegenerative diseases are shown in Table 2.

\section{Challenges of Nanoparticle Drug Delivery in the Management of AD}

The application of nanodelivery drugs in the management of AD has some challenges despite the advantages. A search in the scientific literature showed that clinical activities of nanodelivered solutions for AD are scarce in comparison to cancer and other diseases (Wen et al., 2017). The industrial perspectives, processing, cost, and comparable benefits of using nanodelivery systems for AD treatment are also down-played (Wen et al., 2017). This can limit the production of nano-based drug delivery systems for AD. Many studies have been carried out on animals; however, there is the need to step up research from lower animals to higher ones and then to human trials. This is crucial because no current evidence has been documented showing the effectiveness and safety boundary of nanoparticles in patients having AD (Kassem et al., 2020). The physicochemical properties of nanoparticles are also important aspects requiring consideration in utilizing the delivery system for AD management. For example, sizes lower than $100 \mathrm{~nm}$ are preferable for use in neurodegenerative ailments like AD; higher sizes affect the biodistribution and bioavailability of embedded drugs (Hoshyar et al., 2016).

The stability of nanoparticulate formulations is also of importance as the aggregation of dispersed particles in the blood must be prevented, otherwise toxicity can occur (Gnach et al., 2015). Where gene-targeting brain delivery is to be used, the invasive method must be avoided in delivering the drug into the brain tissues, otherwise the blood-brain barrier may become injured; an example is the PEGylated immune-liposomes via receptor-mediated transcytosis (Kabanov and Batrakova, 2017). Furthermore, whenever there is elongated blood circulation time, some nanoparticles, e.g., PEGylated nanoparticles, will offer lower uptake and prolonged time (Ou et al., 2018). The safety of nanodelivery systems in AD management and other vital areas are challenging for the uptake of nanodelivery systems in brain infirmities. Cost-effectiveness is another major challenge in the application of nanodelivered solutions for $\mathrm{AD}$. Clinical trials are expensive studies that will ultimately add to the cost on the patient thus reducing the number of patients who can benefit from the nanodelivered medications (Wen et al., 2017).

\section{Future Perspectives on the Management of AD}

The FDA has not approved a new drug for AD in the last 17 years, but the organization plans to decide on Aducanumab, a new drug produced by Biogen Inc. for the treatment of $\mathrm{AD}$ in

Table 2. Patents of nanoparticulate delivery systems for neurodegenerative diseases.

\begin{tabular}{|c|c|c|c|c|}
\hline Product & Institution & Patent No & Properties & Inventor \\
\hline Nanoparticle-based technology & $\begin{array}{l}\text { Medinova Medical Consulting GmbH, } \\
\text { Germany }\end{array}$ & US6117454 & $\begin{array}{l}\text { Enables BBB crossing with improved drug } \\
\text { distribution and efficacy }\end{array}$ & $\begin{array}{l}\text { Kreuter J, Alyautdin R, } \\
\text { Karkevich D, Sabel B. }\end{array}$ \\
\hline $\begin{array}{l}\text { Patents on brain permeable } \\
\text { nanoparticles }\end{array}$ & & US6607708 & $\begin{array}{l}\text { Promotes penetration of drugs or diagnostic } \\
\text { agents across the BBB }\end{array}$ & Saluja V, Chopra D \\
\hline Nanogels with polyion polymer & University of Nebraska. & US6696089 & Site-specific delivery & Kabanov A, Vinogradov S \\
\hline $\begin{array}{l}\text { Differential delivery of therapeutic } \\
\text { agents across BBB }\end{array}$ & $\begin{array}{l}\text { National Institute of Health (NIH), } \\
\text { Department of Health and Human Services }\end{array}$ & US5124146 & $\begin{array}{l}\text { Utilizes drug neutralization technology, and } \\
\text { the selective permeability }\end{array}$ & Neuwelt EA \\
\hline $\begin{array}{l}\text { An improved method for diagnosing and } \\
\text { characterizing brain lesion }\end{array}$ & Oregon State Board of Higher Education & US5059415 & Diagnosis of Alzheimer's disease & Neuwelt EA \\
\hline
\end{tabular}


March 2021 (Newton, 2020). The drug is a human monoclonal antibody engineered in a laboratory, and there are speculations that if approved, its coverage may be limited. This is probably due to debatable efficacy, high cost, and safety concerns (Budson, 2020).

For the future, magnetic nanoparticles, dendrimers, and nanoemulsions are fertile areas to explore for their potential technological applications (Harilal et al., 2019). Biocompatible nanoparticles will make a significant impact in the next 10 years and douse the safety concerns of nanodelivered medications in AD.

In the future, healthcare providers will need to do more on preventive measures for $\mathrm{AD}$ than treatment. According to the National Health Service, the risk of AD is lesser in people who sustain social and mental activities in addition to living healthy (NHS, 2018). Examples of mental and social activities which can prevent $\mathrm{AD}$ and other neurodegenerative ailments include reading, learning foreign languages, playing musical instruments, volunteering in local communities, participating in sports, picking up new hobbies, and playing games. Healthy lifestyle measures that will be helpful include not smoking, reducing alcohol intake, exercise, keep blood pressure under control, and maintaining specified diets for diabetics.

\section{CONCLUSION}

$\mathrm{AD}$ is of significant public health importance, especially with increased life expectancy with the attendant increase in the number of the elderly. The management of AD has been negatively influenced due to the failure of most active moieties to permeate the BBB in sufficient concentration. The treatment of AD can be boosted with nanosized formulations containing conventional drugs or bioactive agents, and present opportunities for different methods of preparations to suit the active agents and varied routes of administration to achieve desirable therapeutic patient outcomes. Herbal extracts containing single or multiple herbs or a blend of herbs and minerals have neuroprotective potentials in slowing down the advancement of AD symptoms. These natural products are potential sources of bioactive agents that could be valuable in the management of AD. However, more medical evaluations are essential to further authenticate the usefulness of bioactive agents and novel drug delivery systems in the management AD.

\section{AUTHOR CONTRIBUTIONS}

All authors made substantial contributions to conception and design, acquisition of data, or analysis and interpretation of data; took part in drafting the article or revising it critically for important intellectual content; agreed to submit to the current journal; gave final approval of the version to be published; and agree to be accountable for all aspects of the work. All the authors are eligible to be an author as per the international committee of medical journal editors (ICMJE) requirements/guidelines.

\section{FUNDING}

There is no funding to report.

\section{CONFLICTS OF INTEREST}

The authors report no financial or any other conflicts of interest in this work.

\section{ETHICAL APPROVALS}

Not applicable.

\section{PUBLISHER'S NOTE}

This journal remains neutral with regard to jurisdictional claims in published institutional affiliation.

\section{REFERENCES}

Aggarwal BB, Kumar A, Bharti AC. Anticancer potential of curcumin: preclinical and clinical studies. Anticancer Res, 2003; 23:363-98.

Ali M, Muhammad S, Shah MR, Khan A, Rashid U, Farooq U. Neurologically potent molecules from Crataegus oxyacantha: isolation, anticholinesterase inhibition, and molecular docking. Front Pharmacol, 2017; 8:327.

Ali ME, Lamprecht A. Spray freeze-drying for dry powder inhalation of nanoparticles. Eur J Pharm Biopharm, 2014; 87(3):510-7.

Antunes F, Andrade F, Ferreira D, Morck Nielsen H, Sarmento B. Models to predict intestinal absorption of therapeutic peptides and proteins. Curr Drug Metab, 2013; 14(1):4-20.

Arora S, Gupta S, Narang RK, Budhiraja RD. Amoxicillin loaded chitosan-alginate polyelectrolyte complex nanoparticles as mucopenetrating delivery system for $H$. pylori. Sci Pharm, 2011; 79(3):673-94.

Arumugam K, Subramanian GS, Mallayasamy SR, Averineni RK, Reddy MS, Udupa N. A study of rivastigmine liposomes for delivery into the brain through intranasal route. Acta Pharm, 2008; 8(3):287-97.

Ayaz M, Sadiq A, Junaid M, Ullah F, Subhan F, Ahmed J. Neuroprotective and anti-ageing potentials of essential oils from aromatic and medicinal plants. Aging Neurosci, 2017; 9:168.

Baum L, Lam CW, Cheung SK, Kwok T, Lui V, Tsoh J, Lam L, Leung V, Hui E, Ng C, Woo J, Chiu HF, Goggins WB, Zee BC, Cheng KF, Fong CY, Wong A, Mok H, Chow MS, Ho PC, Ip SP, Ho CS, Yu XW, Lai CY, Chan MH, Szeto S, Chan IH, Mok V. Six-month randomized, placebo-controlled, double-blind, pilot clinical trial of curcumin in patients with Alzheimer disease. J Clin Psychopharmacol, $2008 ; 28(1): 110-3$

Bertram L, Tanzi RE. The genetic epidemiology of neurodegenerative disease. J Clin Invest, 2005; 115(6):1449-57.

Berman MH, Halper JP, Nichols TW, Jarrett H, Lundy A, Huang $\mathrm{JH}$. Photobiomodulation with near infrared light helmet in a pilot, placebo controlled clinical trial in dementia patients testing memory and cognition. J Neurol Neurosci, 2017; 8:1.

Bilati U, Allémann E, Doelker E. Development of a nanoprecipitation method intended for the entrapment of hydrophilic drugs into nanoparticles. Eur J Pharm Sci, 2005; 24(1):67-75.

Bilikiewicz A, Gaus W. Colostrinin (a naturally occurring, proline-rich, polypeptide mixture) in the treatment of Alzheimer's disease. J Alzheimers Dis, 2004; 6:17-26.

Brambilla D, Le Droumaguet B, Nicolas J, Hashemi SH, Wu LP, Moghimi SM, Couvreur P, Andrieux K. Nanotechnologies for Alzheimer's disease: diagnosis, therapy, and safety issues. Nanomedicine, 2011; 7(5):521-40.

Budson AE. https://www.health.harvard.edu/blog/a-newalzheimers-drug-from-advisory-panel-to-fda-whats-at-stake-here2020111221380

Calvo P, Remuñán-López C, Vila-Jato JL, Alonso MJ. Novel hydrophilic chitosan-polyethylene oxide nanoparticles as protein carriers. J Appl Polym Sci, 1997; 63(1):125-32.

Citron M. Alzheimer's disease: strategies for disease modification. Nat Rev Drug Disc, 2010; 9(5):387-98.

Cummings JL, Morstorf T, Zhong K. Alzheimer's disease drugdevelopment pipeline: few candidates, frequent failures. Alzheimers Res Ther, 2014; 6(4):37.

da Silva GB, Scarpa MV, Rossanezi G, do Egito ES, de Oliveira AG. Development and characterization of biocompatible isotropic and anisotropic oil-in-water colloidal dispersions as a new delivery system for methyl dihydrojasmonate antitumor drug. Int J Nanomed, 2014; 9:867-76.

Dang H, Meng MHW, Zhao H, Iqbal J, Dai R, Deng Y, Lv F. Luteolin-loaded solid lipid nanoparticles synthesis, characterization, and 
improvement of bioavailability, pharmacokinetics in vitro and vivo studies J Nanopart Res, 2014; 16:1-10.

De Rosa G, Salzano G, Caraglia M, Abbruzzese A. Nanotechnologies: a strategy to overcome blood-brain barrier. Curr Drug Metab, 2012; 13(1):61-9.

DeKosky ST, Williamson JD, Fitzpatrick AL, Kronmal RA, Ives DG, Saxton JA, Lopez OL, Burke G, Carlson MC, Fried LP, Kuller LH, Robbins JA, Tracy RP, Woolard NF, Dunn L, Snitz BE, Nahin RL, Furberg CD. Ginkgo biloba for prevention of dementia a randomized controlled trial. JAMA, 2008; 300:2253-62.

Dong Y, Ng WK, Shen S, Kim S, Tan RB. Scalable ionic gelation synthesis of chitosan nanoparticles for drug delivery in static mixers. Carbohydr Polym, 2013;94(2):940-945.

Fazil M, Md S, Haque S. Development and evaluation of rivastigmine loaded chitosan nanoparticles for brain targeting. Eur J Pharm Sci, 2012; 47(1):6-15.

Feng Y, Wang X, Yang S, Wang Y, Zhang X, Du X, Sun X, Zhao M, Huang L, Liu R. Resveratrol inhibits beta-amyloid oligomeric cytotoxicity but does not prevent oligomer formation. Neurotoxicology, 2009; 30:986-95

Ferri CP, Prince M, Brayne C, Brodaty H, Fratiglioni L, Ganguli M,. Global prevalence of dementia: a Delphi consensus study. Lancet, 2005; 366(9503):2112-7.

Fonseca-Santos B, Gremião MP, Chorilli M. Nanotechnologybased drug delivery systems for the treatment of Alzheimer's disease. Int J Nanomed, 2015; 10:4981-5003.

Forlenza OV, Diniz BS, Gattaz WF. Diagnosis and biomarkers of predementia in Alzheimer's disease. BMC Med, 2010; 8(1):89-104

Galloway AL, Murphy A, DeSimone JM, Di J, Herrmann JP, Hunter ME, Kindig JP, Malinoski FJ, Rumley MA, Stoltz DM, Templeman TS, Hubby B. Development of a nanoparticle-based influenza vaccine using the PRINT technology. Nanomedicine, 2013; 9(4):523-31.

Gao H, Pang Z, Jiang X. Targeted delivery of nano-therapeutics for major disorders of the central nervous system. Pharm Res, 2013; 30(10):2485-98.

Gaur A, Midha A, Bhatia A. Significance of nanotechnology in medical sciences. Asian J Pharma, 2008; 2(2):80-5.

Gentilucci L, De Marco R, Cerisoli L. hemical modifications designed to improve peptide stability: incorporation of non-natural amino acids, pseudo-peptide bonds, and cyclization. Curr Pharm Design, 2010; 16(28):3185-203

Gervais F, Paquette J, Morissette C, Krzywkowski P, Yu M, Azzi M, Lacombe D, Kong X, Aman A, Laurin J, Szarek WA, Tremblay P. Targeting soluble Abeta peptide with Tramiprosate for the treatment of brain amyloidosis. Neurobiol Aging, 2007; 28(4):537-47.

Ghayur MN, Gilani AH, Ahmed T, Khalid A, Nawaz AS, Agbedahunsi JM, Choudhary MI, Houghton PJ. Muscarinic Ca++ antagonist and specific butyrylcholinesterase inhibitory activity of dried ginger extract might explain its use in dementia. J Pharm Pharmacol, 2008; 60:1375-83.

Gnach A, Lipinski T, Bednarkiewicz A, Rybka J, and Capobianco J.A. Upconverting nanoparticles: assessing the toxicity. Chem Soc Rev. 2015; 44 (6): 1561-1584.

Gratton SE, Pohlhaus PD, Lee J, Guo J, Cho MJ, Desimone JM. Nanofabricated particles for engineered drug therapies: a preliminary biodistribution study of PRINT nanoparticles. J Control Release, 2007; 121(1-2):10-8.

Hagl S, Kocher A, Schiborr C, Kolesova N, Frank J, Eckert GP. Curcumin micelles improve mitochondrial function in neuronal PC12 cells and brains of NMRI mice - impact on bioavailability. Neurochem Int, 2015; 89:234-42.

Harilal S, Jose J, Grace D, Parambi T, Kumar R, Mathew G.E, Uddin M.S, Kim H, Mathew B. Advancements in nanotherapeutics for Alzheimer's disease: current perspectives. J Pharm Pharmacol, 2019; 71:1370-83.

Hishikawa N, Takahashi Y, Amakusa Y, Tanno Y, Tuji Y, Niwa H, Murakami N, Krishna UK. Effects of turmeric on Alzheimer's disease with behavioral and psychological symptoms of dementia. AYU, 2012; 33(4):499-504.

Ho L, Purohit D, Haroutunian V, Luterman JD, Willis F, Naslund J, Buxbaum JD, Mohs RC, Aisen PS, Pasinetti GM. Neuronal cyclooxygenase-2 expression in the hippocampal formation as a function of the clinical progression of Alzheimer disease. Arch Neurol, 2001; 58:487-92. Hoshyar N, Gray S, Han H, Bao G. The effect of nanoparticle size on in vivo pharmacokinetics and cellular interaction. Nanomedicine, 2016; 11(6):673-92.

Howes MR, Houghton P. Acetylcholinesterase inhibitors of natural origin. Int J Biomed Pharm Sci, 2009; 3:67-86.

Hu X, Guo Y, Wang L, Hua D, Hong Y, Li J. Coenzyme Q ${ }_{10}$ nanoparticles prepared by a supercritical fluid-based method. J Supercrit Fluids, 2011; 57(1):66-72.

Ito K, Miyazawa K, Matsumoto F. Amino acid composition of the ethanolic extractives from 31 species of marine red algae. Hiroshima Daigaku Suichikusangakubu Kiyo, 1977; 16:77-90.

Jeon SY, Kwon SH, Seong YH, Bae K, Hur JM, Lee YY, Suh DY, Song KS. Beta-Secretase (BACE 1)-inhibiting stilbenoids from Smilax Rhizoma. Phytomedicine, 2007; 14:403-8.

Jin Y, Wen J, Garg S, Liu D, Zhou Y, Teng L, Zhang W. Development of a novel niosomal system for oral delivery of Ginkgo biloba extract. Int J Nanomed, 2013; 9(2):208-45.

Jo YJ, Kwon YJ. Characterization of $\beta$-carotene nanoemulsions prepared by microfluidization technique. Food Sci Biotechnol, 2014; 23(1):107-13.

Joshi M, Tiwari G, Tiwari R, Srivastava B. Nanomedicine to improve drug delivery outcomes. Chronicles of Young Scientist, 2012; 3(4):258-68.

Joshi SA, Chavhan SS, Sawant KK. Rivastigmine-loaded PLGA and PBCA nanoparticles: preparation, optimization, characterization, in vitro and pharmacodynamic studies. Eur J Pharm Biopharm, 2010; 76(2):189-99.

Kabanov AV, Batrakova EV. Polymer nanomaterials for drug delivery across the bloodbrain barrier. In: Ikezu T, Gendelman HE (eds.) Neuroimmune pharmacology, Springer, Berlin, Germany, pp 847-68, 2017.

Kabanov AV, Vinogradov SV. Nanogel networks including polyion polymer fragments and biological agent compositions thereof US6696089B2, 2004

Kamal MA, Greig NH, Alhomida AS, Al-Jafari AA. Kinetics of human acetylcholinesterase inhibition by the novel experimental Alzheimer therapeutic agent, tolserine. Biochem Pharmacol, 2000; 60(4):561-70.

Kassem LM, Ibrahim NA, Farhana SA. Nanoparticle therapy is a promising approach in the management and prevention of many diseases: does it help in curing Alzheimer disease? Hindawi J Nanotechnol, 2020; Article ID 8147080:8.

Khalil M, Teunissen CE, Otto M, Piehl F, Sormani MP, Gattringer T, Barro C, Kappos L, Comabella M, Fazekas F, Petzold A, Blennow $\mathrm{K}$, Zetterberg H, Kuhle J. Neurofilaments as biomarkers in neurological disorders. Nat Rev Neurol, 2018;14(10):577-89.

Kim J, Lee HJ, Lee KW. Naturally occurring phytochemicals for the prevention of Alzheimer's disease. J Neurochem, 2010; 112(6):1415-30.

Kreuter, J. Nanoparticulate systems for brain delivery of drugs. Adv Drug Deliv Rev, 2001; 47:65-81.

Kreuter J, Karkevich DA, Sable BA, Alayutdin RN. Drug targeting to the nervous system by nanoparticles. US6117454A, 2000.

Kuszewski JC, Wong RHX, Howe PRC. Can curcumin counteract cognitive decline? Clinical Trial evidence and rationale for combining $\omega-3$ fatty acids with curcumin. Adv Nutr, 2018; 9(2):105-13.

Lazar AN, Mourtas S, Youssef I, Youssef I, Parizot C, Dauphin A, Delatour B, Antimisiaris SG, Duyckaerts C. Curcumin-conjugated nanoliposomes with high affinity for $\mathrm{A} \beta$ deposits: possible applications to Alzheimer disease. Nanomedicine, 2013; 9(5):712-21.

Lee HG, Zhu X, Castellani RJ, Nunomura A, Perry G, Smith MA. Amyloid-beta in Alzheimer disease: the null versus the alternate hypotheses. J Pharmacol Exp Ther, 2007; 321(3):823-9. 
Lee L, Hancocks R, Noble I, Norton IT. Production of water-inoil nanoemulsions using high-pressure homogenisation: a study on droplet break-up. J Food Eng, 2014a; 131:33-7.

Lee MS, Wahlqvist ML, Chou YC, Fang WH, Lee JT, Kuan JC, Liu HY, Lu TM, Xiu L, Hsu CC, Andrews ZB, Pan WH. Turmeric improves post-prandial working memory in pre-diabetes independent of insulin. Asia Pac J Clin Nutr, 2014b; 23(4):581-91.

Leszek J, Inglot $\mathrm{AD}$, Janusz $\mathrm{M}$, Lisowski J, Krukowska $\mathrm{K}$, Georgiades JA. Colostrinin ${ }^{\circledR}:$ a proline-rich polypeptide (PRP) complex isolated from ovine colostrum for treatment of Alzheimer's disease. A Double-Blind, Placebo-Controlled Study. Arch Immunol Ther Exp (Warsz), 1999; 47:377-85.

Ma X, Tan C, Zhu D, Gang DR, Xiao P. Huperzine A from Huperzia species-an ethnopharmacological review. J Ethnopharmacol, $2007 ; 113: 15-34$

Mainardes RM, Evangelista RC. Praziquantel-loaded PLGA nanoparticles: preparation and characterization. J Microencapsul, 2005; 22(1):13-24.

Mainardes RM, Gremião MPD. Nanoencapsulation and characterization of zidovudine on poly(L-lactide) and poly(L-lactide)poly(ethylene glycol)-blend nanoparticles. J. Nanosci Nanotechnol, 2012; 12(11):8513-21.

Mainardes RM, Urban MC, Cinto PO, Chaud MV, Evangelista RC, Gremião MP. Liposomes and micro/nanoparticles as colloidal carriers for nasal drug delivery. Curr Drug Deliv, 2006; 3(3):275-85.

Malhotra M, Tomaro-Duchesneau C, Prakash S. Synthesis of TAT peptide-tagged PEGylated chitosan nanoparticles for siRNA delivery targeting neurodegenerative diseases. Biomaterials, 2013; 34(4):1270-80.

Marambaud P, Zhao H, Davies P. Resveratrol promotes clearance of Alzheimer's disease amyloid-beta peptides. J Biol Chem, 2005; 280:37377-82.

Masserini M. Nanoparticles for brain drug delivery. ISRN Biochem, 2013; Article ID 238428:18.

Mazzarino L, Coche-Guérente L, Labbé P, Lemos-Senna E, Borsali R. On the mucoadhesive properties of chitosan-coated polycaprolactone nanoparticles loaded with curcumin using quartz crystal microbalance with dissipation monitoring. J Biomed Nanotechnol, 2014; 10(5):787-94.

Merit J, Edeas M, Bricaire F. Neurodegenerative diseases and oxidative stress. Biomed Pharmacother, 2004; 58(1):39-46. doi: 10.1016/j. biopha.2003.11.004

Morgan D. Immunotherapy for Alzheimer's disease. J Intl Med, 2011; 269(1):54-63.

Mortimer JA, Borenstein AR, Gosche KM, Snowdon DA. Very early detection of Alzheimer neuropathology and the role of brain reserve in modifying its clinical expression. J Geriatr Psychiatry Neurol, 2005; 18(4):218-23

Mourtas S, Lazar AN, Markoutsa E, Duyckaerts C, Antimisiaris SG. Multifunctional nanoliposomes with curcumin-lipid derivative and brain targeting functionality with potential applications for Alzheimer disease. Euro J Med Chem, 2014; 80:175-83. 461:895-7.

Mucke L. Neuroscience: Alzheimer's Disease. Nature, 2009;

Muller RH, Mader K, Gohla S. Solid lipid nanoparticles (SLN) for controlled active delivery - a review of the state of art. Eur J Pharm Biopharm, 2000; 50:161-77.

Murakami H, Kobayashi M, Takeuchi H, Kawashima Y. Preparation of poly(dl-lactide-co-glycolide) nanoparticles by modified spontaneous emulsification solvent diffusion method. Int J Pharm, 1999; 187(2):143-52.

Mutlu NB, Değim Z, Yılmaz Ş, Eşsiz D, Nacar A. New perspective for the treatment of Alzheimer diseases: liposomal rivastigmine formulations. Drug Dev Ind Pharm, 2011; 37(7):775-89.

Naik SR, Pilgaonkar VW, Panda VS. Evaluation of antioxidant activity of Ginkgo biloba phytosomes in rat brain. Phytother Res, 2006; 20(11):1013-6.

Naz S, Beach J., Heckert B. Cerium oxide nanoparticles: a "radical" approach to neurodegenerative disease treatment. Nanomedicine, 2017; 12(5):545-53.
Nazem A, Mansoori GA. Nanotechnology for Alzheimer's disease detection and treatment. Insciences J, 2011; 1(4):169-93.

Nazem A, Mansoori GA. Nanotechnology solutions for Alzheimer's disease: advances in research tools, diagnostic methods and therapeutic agents. J Alzheimers Dis, 2008; 13(2):199-223.

Nestor PJ, Scheltens P, Hodges JR. Advances in the early detection of Alzheimer's disease. Nat Med, 2004; 10(Suppl):S34-41.

Neurochem. Memory loss? VIVIMIND ${ }^{\mathrm{TM}}$ Protects Memory Function, 2010. Available via http:// www.vivimind.com/home.aspx

Neuwelt EA. Differential delivery of therapeutic agents across the blood-brain barrier. US5124146 A, 1992.

Neuwelt EA. Method for diagnostically imaging lesions in the brain inside a blood-brain barrier. US5059415 A, 1991.

Newton N. Biogen's aducanumab in AD unlikely to be wellcovered by payers, with FDA approval prospects mixed, 2020. Available via https://www.clinicaltrialsarena.com/comment/biogen-aducanumabalzheimers-fda/ (Accessed 29 December 2020).

NHS. Prevention-Alzheimer's disease, 2018. Available via https://www.nhs.uk/conditions/alzheimers-disease/prevention/ (Accessed 29 December 2020).

Nordberg A, Hellstrom-Lindahl E, Lee M, Johnson M, Mousavi M, Hall R, Perry E, Bednar I, Court J. Chronic nicotine treatment reduces beta amyloidosis in the brain of a mouse model of Alzheimer's disease. J Neurochem, 2002; 81:655-8.

Obulesu M, Rao DM. Effect of plant extracts on Alzheimer's disease: An insight into therapeutic avenues. J Neurosci Rural Pract, 2011; 2(1):56-61. doi: 10.4103/0976-3147.80102

Oddo S, Caccamo A, Green KN, Liang K, Tran L, Chen Y, Leslie FM, LaFerla FM. Chronic nicotine administration exacerbates tau pathology in a transgenic model of Alzheimer's disease. Proc Natl Acad Sci USA, 2005; 102:3046-51.

OECD. Dementia prevalence in OECD, Health at a Glance: Europe 2010. OECD Publishing, Paris, France, pp 54-55, 2010.

Ono K, Hasegawa K, Yamada M, Naiki H. Nicotine breaks down preformed Alzheimers' beta-amyloid fibrils in vitro. Biol Psychiatry, 2002; 52:880-6.

Onor ML, Trevisiol M, Aguglia E. Rivastigmine in the treatment of Alzheimer's disease: an update. Clin Interv Aging, 2007; 2(1):17-32.

Ou H, Cheng T, Zhang Y. Surface-adaptive zwitterionic nanoparticles for prolonged blood circulation time and enhanced cellular uptake in tumor cells. Acta Biomater, 2018; 65:339-48.

Pappolla M, Bozner P, Soto C, Shao H, Robakis NK, Zagorski M, Frangione B, Ghiso J. Inhibition of Alzheimer beta fibrillogenesis by melatonin. J Biol Chem, 1998; 273:7185-8.

Pardridge W. M. The blood-brain barrier: bottleneck in brain drug development. NeuroRx, 2005; 2(1):3-14.

Pasic MD, Diamandis EP, McLaurin J, Holtzman DM, SchmittUlms G, Quirion R. Alzheimer disease: advances in pathogenesis, diagnosis, and therapy. Clin Chem, 2011; 57(5):664-9.

Patel PA, Patil SC, Kalaria DR, Kalia YN, Patravale VB. Comparative in vitro and in vivo evaluation of lipid-based nanocarriers of Huperzine A. Int J Pharm, 2013; 446(1-2):16-23.

Patel Z, Patel B, Patel S, Pardeshi C. Nose to brain targeted drug delivery bypassing the blood-brain barrier: an overview. Drug Invention Today, 2012; 31(4):610-5.

Pehlivan SB. Nanotechnology-based drug delivery systems for targeting, imaging and diagnosis of neurodegenerative diseases. Pharm Res, 2013; 30(10):2499-511.

Pezzuto JM. Resveratrol: twenty years of growth, development and controversy. Biomol Ther (Seoul), 2019; 27(1):1-14. doi:10.4062 biomolther.2018.176

Puglia C, Frasca G, Musumeci T, Rizza L, Puglisi G, Bonina F, Chiechio S (2012) Curcumin loaded NLC induces histone hypoacetylation in the CNS after intraperitoneal administration in mice. Eur J Pharm Biopharm, 2012; 81:288-93. 
Ramírez-Garza SL, Laveriano-Santos EP, Marhuenda-Muñoz M, Storniolo CE, Tresserra-Rimbau A, Vallverdú-Queralt A, LamuelaRaventós RM. Health effects of resveratrol: results from human intervention trials. Nutrients, 2018; 10(12):1892. doi: 10.3390/nu10121892

Ringman JM, Frautschy SA, Teng E, Begum AN, Bardens J, Beigi M, Gylys KH, Badmaev V, Heath DD, Apostolova LG, Porter V, Vanek Z, Marshall GA, Hellemann G, Sugar C, Masterman DL, Montine TJ, Cummings JL, Cole GM. Oral curcumin for Alzheimer's disease: tolerability and efficacy in a 24-week randomized, double-blind, placebocontrolled study. Alzheimers Res Ther, 2012; 4(5):43.

Rocha S. Targeted drug delivery across the blood-brain barrier in Alzheimer's disease. Curr Pharm Des, 2013; 19(37):6635-46.

Roney C, Kulkarni P, Arora V, Antich P, Bonte F, Wu A, Mallikarjuana NN, Manohar S, Liang HF, Kulakarni AR, Sung HW, Sairam M, Aminabhavi TM. Targeted nanoparticles for drug delivery through the blood-brain barrier for Alzheimer's Disease. J Control Release, 2005; 108(2-3):193-214.

Rossignol E, Debiton E, Fabbro D, Moreau P, Prudhomme M, Anizon F. In vitro antiproliferative activities and kinase inhibitory potencies of meridianin derivatives. Anti-Cancer Drugs, 2008; 19:789-92.

Rubin LL, Staddon JM. The cell biology of the blood-brain barrier. Annu Rev Neurosci, 1999; 22:11-28.

Saini R, Alagh P, Carpenter B. Nurses and Alzheimer's disease: A holistic perspective. Indian J Public Health, 2012; 56:318-9.

Sarin H, Kanevsky AS, Wu H, Brimacombe KR, Fung SH, Sousa AA. Effective transvascular delivery of nanoparticles across the blood-brain tumour barrier into malignant glioma. J Transl Med, 2008; 6:Article 80.

Schleh C, Semmler-Behnke M, Lipka J, Wenk A, Hirn S, Schäffler M. Size and surface charge of gold nanoparticles determine absorption across intestinal barriers and accumulation in secondary target organs after oral administration. Nanotoxicol, 2012; 6:36-46.

Schwartz MF, Buxbaum LJ, Ferraro M, Veramonti T, Segal M. The naturalistic action test. Thames Valley Test Company, Bury St. Edmunds, UK, 2003.

Sloane PD, Zimmerman S, Suchindran C, Reed P, Wang L, Boustani M. The public health impact of Alzheimer's disease, 2000-2050: potential implication of treatment advances. Annu Rev Public Health, 2002; $23: 213-31$.

Sood S, Jain K, Gowthamarajan K. Delivery of neuroprotective polyphenol to the brain via an intranasal route for the management of Alzheimer's disease. Alzheimers Dement, 2013; 9(4):P299.

Sood S, Jain K, Gowthamarajan K. Optimization of curcumin nanoemulsion for intranasal delivery using design of experiment and its toxicity assessment. Colloids Surf B Biointerf, 2014; 113:330-7.

Souto EB, Severino P, Santana MHA. Preparação de nanopartículas poliméricas a partir da polimerização de monômeros: parte I [Preparation of polymeric nanoparticles by polymerization of monomers: part I]. Polímeros, 2012; 22:96-100.

Spuch C, Navarro C. Liposomes for targeted delivery of active agents against neurodegenerative diseases (Alzheimer's disease and Parkinson's disease). J Drug Del, 2011: Article ID 469679:12.

Stafford GI, Pedersen PD, Jäger AK, Van Staden J. Monoamine oxidase inhibition by southern African traditional medicinal plants. South African J Bot, 2007; 73(3):384-90.

Tang L, Wang R, Tang X. Effects of Huperzine A on secretion of nerve growth factor in cultured rat cortical astrocytes and neurite outgrowth in rat PC12 cells. Acta Pharmacol Sin, 2005; 26:673-8.
Taniguchi S, Suzuki N, Masuda M, Hisanaga S, Iwatsubo T, Goedert M, Hasegawa M. Inhibition of heparin-induced tau filament formation by phenothiazines, polyphenols, and porphyrins. J Biol Chem, 2005; 280(9):7614-23.

Uabundit N, Wattanathorn J, Mucimapura S, Ingkaninan K. Cognitive enhancement and neuroprotective effects of Bacopa monnieri in Alzheimer's disease model. J Ethnopharmacol, 2010; 127:26-31.

Wang B, Wang H, Wei Z, Song Y, Zhang L, Chen H. Efficacy and safety of natural acetylcholinesterase inhibitor huperzine A in the treatment of Alzheimer's disease: an updated meta-analysis. J Neural Transm, 2009; 116:457-65.

Wang F, Cui N, Yang L. Resveratrol rescues the impairments of hippocampal neurons stimulated by microglial over-activation in vitro. Cell Mol Neurobiol, 2015; 35:1003-15.

Wang J, Sun X, Zhang Z. Enhanced brain targeting by synthesis of 3',5'- Dioctanoyl-5-Fluoro-2'-Deoxyuridine and incorporation into solid lipid nanoparticles. Eur J Pharm Biopharm, 2002; 54:285-90.

Wang R, Yan H, Tang X. Progress in studies of huperzine A, a natural cholinesterase inhibitor from Chinese herbal medicine. Acta Pharmacol Sin, 2006; 27:1-26.

Wang Y, Xu H, Fu Q, Ma R, Xiang J () Protective effect of resveratrol derived from Polygonum cuspidatum and its liposomal form on nigral cells in parkinsonian rats. J Neurol Sci, 2011; 304:29-34.

Watkins PB, Zimmerman HJ, Knapp MJ, Gracon SI, Lewis KW. Hepatotoxic effects of tacrine administration in patients with Alzheimer's disease. JAMA, 1994; 271(13):992-8.

Wen MM, El-Salamouni NS, El-Refaie WS, Heba A, Hazzah HA, Ali MM, Tosi G, Farid RM, Blanco-Prieto MJ, Billa N, Hanafy AS. Nanotechnology-based drug delivery systems for Alzheimer's disease management: technical, industrial, and clinical challenges. J Control Rel, 2017; 245:95-107.

Williams P, Sorribas A, Howes MR. Natural products as a source of Alzheimer's drug leads. Nat Prod Rep, 2011; 28(1):48-77.

Wissing SA, Kayser O, Muller RH. Solid lipid nanoparticles for parenteral drug delivery. Adv Drug Deliv Rev, 2004; 56:1257-72.

Yang F, Lim GP, Begum AN, Ubeda OJ, Simmons MR, Ambegaokar SS, Chen PP, Kayed R, Glabe CG, Frautschy SA, Cole GM. Curcumin inhibits formation of amyloid beta oligomers and fibrils, binds plaques, and reduces amyloid in vivo. J Biol Chem, 2005; 280:5892-901.

Yiannopoulou KG, Papageorgiou SG. Current and future treatments for Alzheimer's disease. Ther Adv Neurol Disord, 2013; 6(1):1933. doi: $10.1177 / 1756285612461679$

Zarotsky V, Sramek JJ, Cutler NR. Galantamine hydrobromide: an agent for Alzheimer's disease. Am J Health Syst Pharm, 2003; 60 $446-52$.

Zhao G, Zang SY, Jiang ZH, Chen YY, Ji XH, Lu BF, Wu JH, Qin GW, Guo LH. Postischemic administration of liposome-encapsulated luteolin prevents against ischemia-reperfusion injury in a rat middle cerebral artery occlusion model. J Nutr Biochem, 2011; 22:929-36.

How to cite this article:

Odeku OA, Ajala TO. Nanodelivery systems for Alzheimer's disease: Prospects of natural therapeutic agents. J Appl Pharm Sci, 2021; 11(11):001-010. 